American Journal of Pharmacology and Toxicology 2 (3): 123-129, 2007

ISSN 1557-4962

(C) 2007 Science Publications

\title{
Anti-hyperglycaemic and Hypolipidemic Effects of Ocimum basilicum Aqueous Extract in Diabetic Rats
}

\author{
${ }^{1}$ N.A. Zeggwagh, ${ }^{2}$ T. Sulpice and ${ }^{1}$ M. Eddouks \\ ${ }^{1}$ UFR PNPE, BP.21, Errachidia, 52000, Morocco \\ ${ }^{2}$ Physiogenex, Toulouse, France
}

\begin{abstract}
The hypoglycaemic and hypolipidemic effects of the aqueous extract of Ocimum basilicum (OB) whole plant were investigated in normal and streptozotocin (STZ) diabetic rats. After a single oral administration, OB significantly reduced blood glucose levels in normal $(\mathrm{p}<0.01)$ and diabetic rats $(\mathrm{p}<0.001)$. After 15 days of repeated oral administration, OB produced a potent reduction on blood glucose levels $(\mathrm{p}<0.001)$ in diabetic rats and a less reduction in normal rats $(\mathrm{p}<0.05)$. Total plasma cholesterol and triglycerides levels were significantly reduced after repeated oral administration in diabetic rats $(\mathrm{p}<0.001)$ and $(\mathrm{p}<0.05)$ respectively. However, no change was observed in total plasma cholesterol and triglycerides levels in normal rats after both single and repeated oral administration. In addition, plasma insulin levels and body weight remained unchanged over 15 days of oral administration in normal and diabetic rats. We conclude that the aqueous extract of $\mathrm{OB}$ exhibits potent anti-hyperglycaemic and hypolipidemic activities in diabetic rats without affecting basal plasma insulin concentrations.
\end{abstract}

Key words: Ocimum basilicum, aqueous extract, oral administration, anti-hyperglycaemic

\section{INTRODUCTION}

Diabetes mellitus is now taking place as serious disease with burden financial $\operatorname{cost}^{[1]}$. The number of people suffering from diabetes is actually estimated to 151 millions and this number is projected to double in the next decade ${ }^{[2]}$. Surely, current diabetes pharmacotherapy gives sharp and good control of blood glucose levels but the efficiency became strictly reduced after long term use $\mathrm{e}^{[3]}$. In addition to elevated blood glucose levels, diabetes is generally accompanied with lipid metabolism abnormality communally known as diabetic dyslipidemia ${ }^{[4]}$. Unfortunately, the control of diabetic dyslipidemia did not always accompany the control of blood glucose levels ${ }^{[5]}$.

More than 1200 plants species are world wild used in diabetes phytotherapy and experimental studies support the hypoglycaemic activity of a large number of these plants ${ }^{[6]}$. In addition to correction of blood glucose levels, several hypoglycaemic plants are potential in ameliorating lipid metabolism abnormalities of diabetes mellitus ${ }^{[7]}$. Thus, the study of plant hypoglycaemic and hypoglipidemic activities may give new pharmacological approach in the treatment of diabetes mellitus ${ }^{[8]}$.

Ocimum basilicum (OB) is a plant belonging to Lamiacea family locally known as "Lahbak albaldi".
According to the ethnopharmacological survey in the Tafilalet region, OB is used on the local phototherapy in the treatment of diabetes and cardiovascular diseases $^{[9]}$.

The present study was undertaken to evaluate the hypoglycaemic and hypolipidemic activities of a single and repeated oral administration of the aqueous OB extract at a dose of $20 \mathrm{mg} \mathrm{kg}^{-1}$ body weight in normal and streptozotocin-induced diabetic rats. Vanadate, a hypoglycaemic and hypolipidemic agent ${ }^{[10,11]}$ was used as a reference drug.

\section{MATERIALS AND METHODS}

Plant material: Specimens of Ocimum basilicum were collected from the Tafilalet region (semi-arid area) of Morocco in May-June 2001 and air-dried at $40^{\circ} \mathrm{C}$. The plant was previously identified and authenticated by $\mathrm{Pr}$. M. Rejdali (Agronomy and Veterinary Institute, Rabat) and a voucher specimen (EM15) was deposited at the herbarium of the Faculty of Sciences and Techniques Errachidia.

Preparation of the aqueous extract: Plant material was prepared according to the traditional method used in Morocco (decoction): $1 \mathrm{~g}$ of powdered whole plant mixed with $100 \mathrm{~mL}$ distilled water were boiled for 10

Corresponding Author: Mohamed Eddouks, BP 21, Errachidia, 52000, Morocco Tel: +21255 574497 Fax: +212 55574485 
min and then cooled for $15 \mathrm{~min}$. Thereafter, the aqueous extract was filtered using a Millipore filter (Millipore $0.2 \mathrm{~mm}$, St Quentin en Yvelines, France) to remove particulate matter. The filtrate was then freezedried and the desired dose (mg of lyophilized aqueous extract of per kg body weight) was then prepared and reconstituted in $1.5 \mathrm{~mL}$ of distilled water. The aqueous extracts were prepared daily, just before administration. The extracts obtained were then given orally to different groups at a dose of $20 \mathrm{mg} \mathrm{kg}^{-1}$ body weight. aqueous $\mathrm{OB}$ extract was maroon coloured with a percent yield of $12 \%$ with an average osmolarity of 50 mOsm $\mathrm{kg}^{-1} \mathrm{H}_{2} \mathrm{O}$ and $\mathrm{pH}$ 6.1.

Experimental design: Experiments were performed in adult male Wistar rats weighing from 200-250 g. Animals were housed under standard environmental conditions $\left(23 \pm 1^{\circ} \mathrm{C}, 55 \pm 5 \%\right.$ humidity and a $12 \mathrm{~h}$ light/dark cycle) and maintained with free access to water and a standard laboratory diet (carbohydrates; $30 \%$, proteins; $22 \%$, lipids; $12 \%$, vitamins; 3\%) ad libitum.

Diabetes was induced by intravenous injection of streptozotocin (Sigma, St Louis, Mo, USA) into the tail vein at a dose of $65 \mathrm{mg} \mathrm{kg}^{-1}$ body weight. STZ was extemporaneously dissolved in $0.1 \mathrm{M}$ cold sodium citrate buffer, $\mathrm{pH} 4.5$. After $18 \mathrm{~h}$, animals with fasting blood glucose levels greater than $22 \mathrm{mmol} \mathrm{L}^{-1}$ were considered diabetic and then included in this study.

Normal and diabetic rats were randomly assigned to three different groups ( $\mathrm{n}=6$ for each group). The control group received distilled water; treated groups received aqueous extracts of $\mathrm{OB}$ at a dose of $20 \mathrm{mg}$ $\mathrm{kg}^{-1}$ or sodium-vanadate (Fluka, Chemica, Switzerland) at a dose of $0.8 \mathrm{mg} \mathrm{kg}^{-1}$. All experiments were performed in overnight fasted rats.

Single administration: The drug solutions or vehicle were administered orally by gastric intubation using a syringe once daily at $09 \mathrm{~h}$ a.m. Blood glucose levels were determined in fasted rats, 1, 2, 4 and $6 \mathrm{~h}$ after a single oral administration. Total plasma cholesterol and triglycerides levels were determined before and $6 \mathrm{~h}$ after $\mathrm{OB}$ administration.

Repeated oral administration: Rats were treated once daily for two weeks. Blood glucose levels, plasma triglycerides levels, plasma cholesterol levels and body weight were determined after two, four days, one and two weeks of once daily repeated oral administration.

Determination of parameters: Blood samples were retrieved from the retro-orbital plexus in fasted and anesthetized rats using ether solution inhalation. Blood glucose levels were determined by the glucose oxidase method using a reflective glucometer (Model GX, Ames Miles, Bayer Diagnostics, Genome Biotechnologies, Casablanca, Morocco). Plasma triglycerides and total cholesterol levels were measured using colorimetric method with commercially available kits (Randox, UK). Absorbance was measured at 500 nm. Basal plasma insulin concentrations were determined by radioimmunoassay kit (Pharmacia, Uppsala, Sweden) with a Beta matic counter (Cronex, Dupont, France). The kit included human insulin as standard and 125I-labelled human insulin antibody, which cross reacts with rat insulin.

Statistical analysis: All the data reported are expressed as mean \pm SEM Statistical analysis was performed using the analysis of variance (ANOVA) followed by Bonferroni post tests. The values were considered to be significantly different when the $\mathrm{p}$ value was less than 0.05 compared to the respective control group.

\section{RESULTS}

Effects of $\mathrm{OB}$ aqueous extract administration on blood glucose levels; single oral administration: Figure 1 shows change in blood glucose levels after a single oral administration of aqueous $\mathrm{OB}$ extract at a dose of $20 \mathrm{mg} \mathrm{kg}^{-1}$. In normal treated rats, a significant decrease in blood glucose levels was observed since from the second hour after a single administration $(p<0.001)$ and a further decrease was noticed at the fourth hour $(\mathrm{p}<0.001)$. Afterwards, blood glucose levels remained stable. Vanadate treatment at a dose of $0.8 \mathrm{mg} \mathrm{kg}^{-1}$ produced a slight decrease in blood glucose levels two $(\mathrm{p}<0.01)$ and $4 \mathrm{~h}(\mathrm{p}<0.01)$ afetr oral administration. In STZ rats, the aqueous $\mathrm{OB}$ extract induced a significant decrease in blood glucose levels $4 \mathrm{~h}$ after oral administration $(\mathrm{p}<0.001)$. However, vanadate caused a significant droop in blood glucose levels $4 \mathrm{~h}$ after a single administration $(\mathrm{p}<0.001)$.

Effects of $O B$ aqueous extract administration on blood glucose levels, repeated oral administration: Change in blood glucose levels in normal and diabetic rats over 15 days of daily $\mathrm{OB}$ aqueous extract administration is shown in Fig. 2. In normal rats, a significant reduction in blood glucose levels was observed only after 15 days of repeated oral administration $(\mathrm{p}<0.01)$. There was no change in blood glucose levels in vanadate-treated rats. Relating to STZ rats, significant reduction in blood glucose levels was observed from the fourth day of treatment $(\mathrm{p}<0.001)$, 
Am. J. Pharm. \& Toxicol., 2 (3): 123-129, 2007
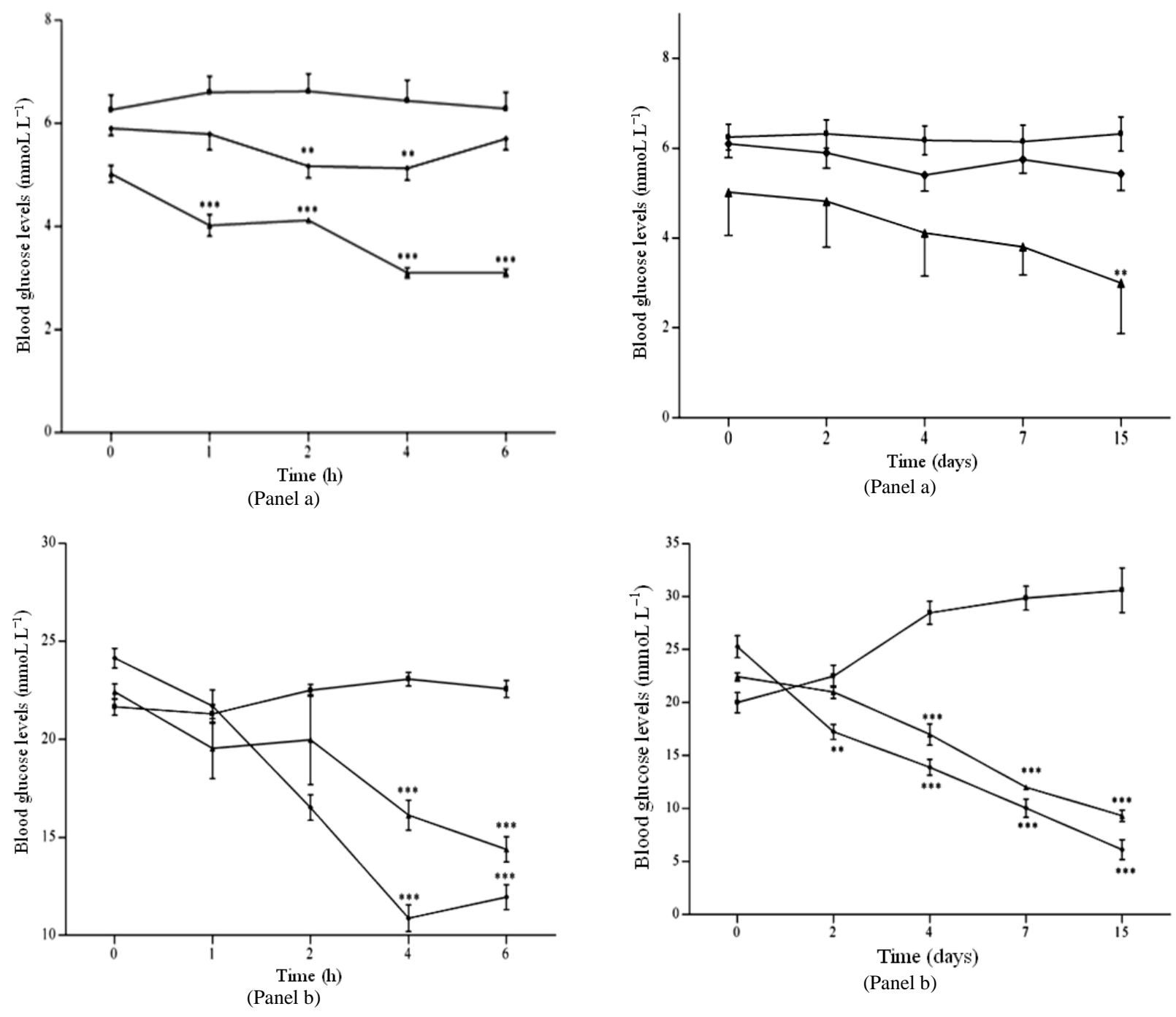

Fig. 1: Plasma glucose levels over $6 \mathrm{~h}$ of a single oral administration of aqueous OB extract $\left(20 \mathrm{mg} \mathrm{kg}^{-1}\right.$ ) in normal (Panel a) and diabetic rats (Panel b). Data are expressed as means \pm SEM, $\mathrm{n}=6$ rats per group. *: $\mathrm{p}<0.05$; $* *: \mathrm{p}<0.01 ; * * *: \mathrm{p}<0.001$, when compared to respective control group. -: Control; $\neg$ : OB extract; $\rightarrow$ : Vanadate

this reduction was more pronounced thereafter reaching an average of $9.32 \pm 0.52 \mathrm{mM}$ at the end of the treatment $(\mathrm{p}<0.001)$. Treatment with vanadate resulted in a reduction in blood glucose levels from the second day $(p<0.01)$. This reduction was maintained until the fifteenth day of treatment $(\mathrm{p}<0.001)$. In contrast, the plasma glucose levels of untreated diabetic rats were dramatically increased during four days of experiments reaching the value of $30.60 \pm 2.10 \mathrm{mM}$ at the 15 th day.

Fig. 2: Plasma glucose levels after once daily repeated oral administration of $\mathrm{OB}$ aqueous extract $\left(20 \mathrm{mg} \mathrm{kg}^{-1}\right.$ ) for 15 days in normal (Panel a) and diabetic rats (Panel b). Data are expressed as means \pm SEM, $\mathrm{n}=6$ rats per group. **: $\mathrm{p}<0.01 ; * * *: \mathrm{p}<0.001$, when compared to respective control group. $\square-$ : Control; $\triangle-$ : $\mathbf{O B}$ extract; $\rightarrow$ : Vanadate

Effect of OB aqueous extract on body weight: Body weight of normal and diabetic rats was measured during the study (Fig. 3). As shown in Fig. 3, aqueous $\mathrm{OB}$ extract did not cause any significant change in body weight after two weeks of treatment in normal rats while treatment with vanadate caused a decrease in body weight at the end of treatment period $(\mathrm{p}<0.01)$. 
Am. J. Pharm. \& Toxicol., 2 (3): 123-129, 2007

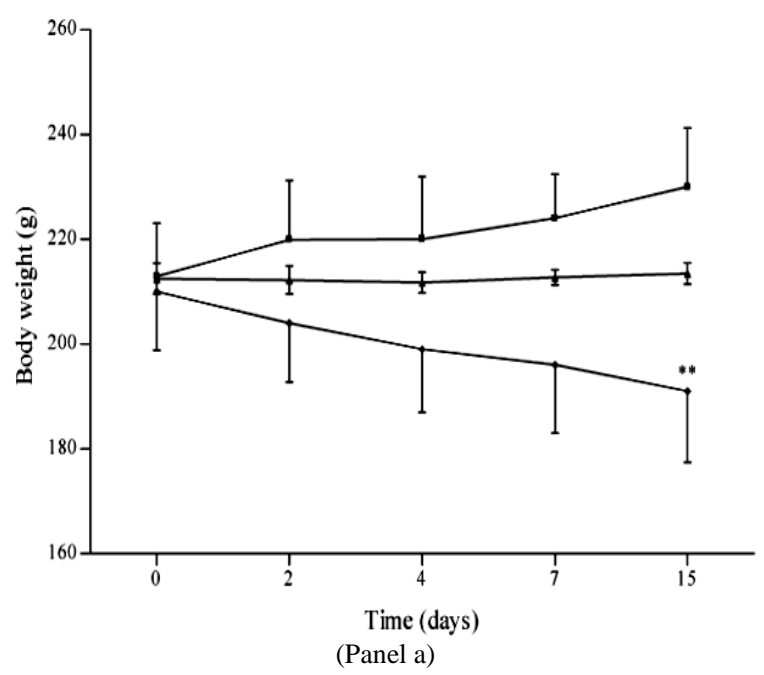

Table 1: Basal plasma insulin concentrations $\left(\mu \mathrm{U} \mathrm{mL}^{-1}\right)$ after repeated oral administration of the aqueous OB extract at a dose of $20 \mathrm{mg} \mathrm{kg}^{-1}$ in normal and diabetic rats. Data are expressed as means \pm SEM, $\mathrm{n}=6$ rats in each group

\begin{tabular}{lll}
\hline & Plasma insulin concentrations $\left(\mu \mathrm{U} \mathrm{mL}^{-1}\right)$ \\
\cline { 2 - 3 } & Day 0 & Day 15 \\
\hline Normal rats & & \\
Control & $35.40 \pm 2.17$ & $36.45 \pm 4.12$ \\
OB & $33.78 \pm 0.33$ & $33.86 \pm 1.24^{\mathrm{NS}}$ \\
Vanadate & $31.81 \pm 3.15$ & $32.71 \pm 3.00^{\mathrm{NS}}$ \\
Diabetic rats & & \\
Control & $7.08 \pm 0.39$ & $6.75 \pm 0.15$ \\
OB & $5.06 \pm 0.32$ & $4.12 \pm 0.23^{\mathrm{NS}}$ \\
Vanadate & $6.05 \pm 0.52$ & $5.72 \pm 0.82^{\mathrm{NS}}$ \\
\hline
\end{tabular}

Table 2: Total plasma cholesterol and plasma triglycerides levels after a single oral administration of $\mathrm{OB}$ aqueous extract (20 $\mathrm{mg} \mathrm{kg}{ }^{-1}$ ) in normal and diabetic rats. Data are expressed as mean \pm SEM, $n=6$ rats per group. NS: Not significant compared to the respective control group. \#: $\mathrm{p}<0.001$ when compared to normal rats

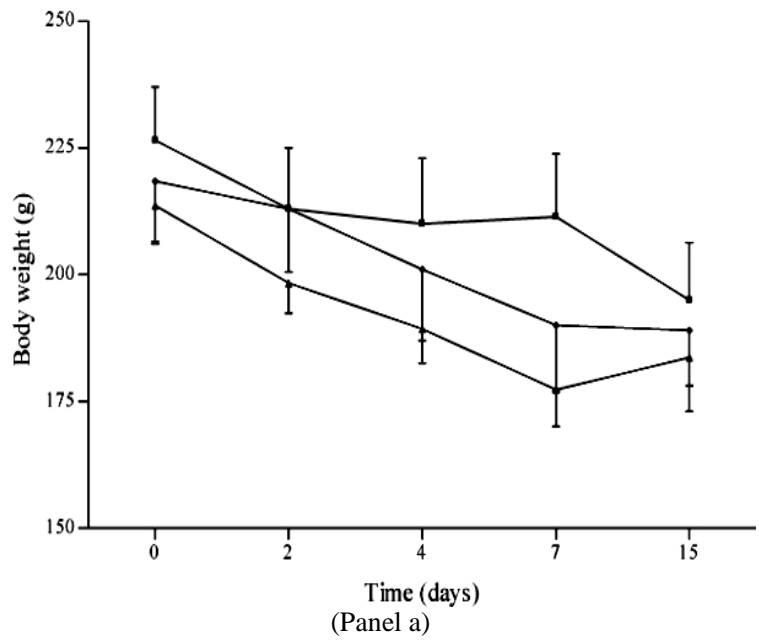

Fig. 3: Body weight change after once daily repeated oral administration of an aqueous OB extract (20 $\mathrm{mg} \mathrm{kg}^{-1}$ ) for 15 days in normal (Panel a) and diabetic rats (Panel b). Data are expressed as mean \pm SEM, $\mathrm{n}=6$ rats per group. $* \mathrm{p}<0.05$; $* *: \mathrm{p}<0.01 ; * * *: \mathrm{p}<0.001$, when compared to respective control group. -- : Control; $\triangle-$ : OB extract; $\rightarrow$ : Vanadate

Effect of $O B$ aqueous extract on basal plasma insulin concentrations: Basal plasma insulin concentrations did not differ significantly in the OBtreated groups when compared to untreated group in both normal and diabetic rats (Table 1). In addition, vanadate treatment did not affect insulin secretion in both normal and STZ rats.

Effect of aqueous OB extract on total plasma cholesterol and triglycerides levels: Single administration: Streptozotocin injection caused a significant increase in the total plasma cholesterol and

\begin{tabular}{lllll}
\hline & \multicolumn{2}{l}{ Total plasma cholesterol levels $\left(\mathrm{mmol} \mathrm{L}^{-1}\right)$} \\
& $-\mathrm{c}$ Normal rats & \multicolumn{2}{l}{ Diabetic rats } \\
Time (h) & 0 & 6 & 0 & 6 \\
\hline Control & $3.27 \pm 0.06$ & $3.20 \pm 0.19$ & $4.2 \pm 0.06^{\#}$ & $4.16 \pm 0.19$ \\
Vana-date & $3.03 \pm 0.1$ & $3.09 \pm 0.6^{\mathrm{NS}}$ & $3.03 \pm 0.1^{\#}$ & $3.06 \pm 0.23^{\mathrm{NS}}$ \\
OB & $3.10 \pm 0.3$ & $3.03 \pm 0.03^{\mathrm{NS}}$ & $4.4 \pm 0.02^{\#}$ & $3.8 \pm 0.23^{\mathrm{NS}}$ \\
Plasma triglycerides levels $\left(\mathbf{m m o l} \mathbf{L}^{-\mathbf{1}}\right)$ & & \\
Control & $2.06 \pm 0.06$ & $2.1 \pm 0.09$ & $3.0 \pm 0.04^{\#}$ & $3.01 \pm 0.19$ \\
Vana-date & $1.98 \pm 0.03$ & $2.03 \pm 0.2^{\mathrm{NS}}$ & $3.17 \pm 0.24^{\#}$ & $3.15 \pm 0.09^{\mathrm{NS}}$ \\
OB & $2.12 \pm 0.03$ & $2.01 \pm 0.02^{\mathrm{NS}}$ & $3.32 \pm 0.03^{\#}$ & $3.25 \pm 0.12$ \\
\hline
\end{tabular}

triglyceride levels $(\mathrm{p}<0.001)$ when compared to normal rats (Table 2). OB aqueous extract failed to reduce plasma triglycerides and cholesterol levels $6 \mathrm{~h}$ after oral administration. No significant change in total plasma cholesterol and triglyceride levels was observed after single oral administration of vanadate in normal and diabetic rats.

Effect of aqueous $O B$ extract on total plasma
cholesterol and administration: Change on total plasma cholesterol and triglycerides levels in normal and diabetic rats during 15 days of oral administration of aqueous $\mathrm{OB}$ extract is shown in Table 3. In normal rats, daily oral administrations of aqueous OB extract over 15 days had no effect on total plasma cholesterol and triglycerides levels. However, vanadate administration reduced total plasma cholesterol levels $(\mathrm{p}<0.001)$ after 15 days of oral administration. Triglyceride levels were reduced from the fourth day $(\mathrm{p}<0.01)$ of treatment and a further reduction was observed in the seventh and fifteenth day of treatment $(\mathrm{p}<0.001)$. 
Am. J. Pharm. \& Toxicol., 2 (3): 123-129, 2007

Table 3: Total plasma cholesterol and triglycerides levels $\left(\mathrm{mmol} \mathrm{L}^{-1}\right)$ after repeated oral administration of aqueous $\mathrm{OB}$ extract $\left(20 \mathrm{mg} \mathrm{kg}^{-1}\right)$ in normal and diabetic rats. Data are expressed as mean \pm SEM, $\mathrm{n}=6$ rats per group

\begin{tabular}{|c|c|c|c|c|c|c|c|c|}
\hline \multirow{3}{*}{$\begin{array}{l}\text { Time } \\
\text { (days) }\end{array}$} & \multicolumn{8}{|c|}{ Total plasma cholesterol levels $\left(\mathrm{mmol} \mathrm{L}^{-1}\right)$} \\
\hline & \multicolumn{4}{|c|}{ Normal rats } & \multicolumn{4}{|l|}{ Diabetic rats } \\
\hline & 0 & 4 & 7 & 15 & 0 & 4 & 7 & 15 \\
\hline Control group & $3.27 \pm 0.06$ & $2.73 \pm 0.07$ & $2.75 \pm 0.01$ & $2.82 \pm 0.06$ & $4.2 \pm 0.06^{\#}$ & $3.85 \pm 0.07$ & $4.42 \pm 0.01$ & $3.75 \pm 0.06$ \\
\hline $\begin{array}{l}\text { Vanadate } \\
\text { treated group }\end{array}$ & $3.03 \pm 0.10$ & $2.73 \pm 0.05$ & $2.53 \pm 0.09$ & $2.16 \pm 0.07 * * *$ & $3.03 \pm 0.1^{\#}$ & $2.73 \pm 0.07 * * *$ & $2.53 \pm 0.09 * * *$ & $2.16 \pm 0.07 * * *$ \\
\hline OB treated group & $3.10 \pm 0.30$ & $2.86 \pm 0.04$ & $2.96 \pm 0.15$ & $3.02 \pm 0.12$ & $4.4 \pm 0.02^{\#}$ & $3.50 \pm 0.4$ & $3.20 \pm 0.2 * * *$ & $2.63 \pm 0.02 * * *$ \\
\hline \multicolumn{9}{|c|}{ Plasma triglycerides levels $\left(\mathrm{mmol} \mathrm{L}^{-1}\right)$} \\
\hline Control group & $2.06 \pm 0.06$ & $1.93 \pm 0.05$ & $1.93 \pm 0.08$ & $1.97 \pm 0.09$ & $3.00 \pm 0.04^{\#}$ & $3.03 \pm 0.35$ & $2.85 \pm 0.42$ & $2.79 \pm 0.26$ \\
\hline $\begin{array}{l}\text { Vanadate } \\
\text { treated group }\end{array}$ & $1.98 \pm 0.03$ & $1.63 \pm 0.03 * *$ & $1.53 \pm 0.03 * * *$ & $1.53 \pm 0.05 * * *$ & $3.17 \pm 0.24^{\#}$ & $2.45 \pm 0.3$ & $2.02 \pm 0.33 *$ & $1.78 \pm 0.29 * *$ \\
\hline OB treated group & $2.12 \pm 0.03$ & $2.10 \pm 0.2$ & $2.10 \pm 0.03$ & $2.13 \pm 0.12$ & $3.32 \pm 0.03^{\#}$ & $3.02 \pm 0.05$ & $2.56 \pm 0.12$ & $2.06 \pm 0.02 *$ \\
\hline
\end{tabular}

In diabetic rats, aqueous $\mathrm{OB}$ extract produced a significant reduction on total plasma cholesterol seven days $(\mathrm{p}<0.01)$ and fifty days $(\mathrm{p}<0.01)$ after once daily oral administration. Triglyceride levels were reduced after 15 days of treatment $(\mathrm{p}<0.05)$. Vanadate administration produced earlier reduction in cholesterol levels from the second day of administration $(\mathrm{p}<0.05)$, a sustained reduction was observed until the end of treatment period $(\mathrm{p}<0.001)$.

\section{DISCUSSION}

Certainly, insulin and oral hypoglycaemic agents i.e., sulphonylurea, alpha-glucosidase inhibitor and thiazolidinediones greatly ameliorate diabetes control ${ }^{[12]}$ but efforts remain necessary to discover new hypoglycaemic agents from plants ${ }^{[13]}$. Previous studies have demonstrated that in addition to the hypoglycaemic activity, several plants possess plasma lipid lowering activity in animal model of diabetes mellitus $^{[14-18]}$.

The genus Ocimum comprises some 65 plant species world wild used in the traditional medicine. OB is commonly used in as culinary herbs in the Mediterranean region. Previous studies reveal the antimicrobial $^{[19]}$, insecticidal ${ }^{[20]}$ and anticarcinogenic $^{[21]}$ activities of different $\mathrm{OB}$ extracts. Furthermore, Ocimum sanctum possess antihyperglycaemic effect in alloxan-diabetic rats ${ }^{[22]}$. In the current work, we aim to evaluate the hypoglycaemic and lipid lowering activity of aqueous $\mathrm{OB}$ extract at a dose of $20 \mathrm{mg} \mathrm{kg}^{-1}$ in normal and diabetic rats after both a single and 15 days of repeated oral administration. Vanadate was used as a reference drug mimicking several insulin actions in vivo such as stimulation of hexose uptake, the stimulation of lipogenesis and the inhibition of lipolysis ${ }^{[23]}$. We have used streptozotocin-induced rats as a recommended animal model of insulin dependent diabetes mellitus. Intravenous injection of streptozotocin at a dose of 65 $\mathrm{mg} \mathrm{kg}^{-1}$ caused an irreversible pancreatic beta cell destruction leading to hypoinsulinemia and severe hyperglycaemia ${ }^{[24]}$ and the increase in blood glucose levels is accompanied by a parallel increase in plasma cholesterol and triglycerides levels ${ }^{[25]}$. Thus, streptozotocin-induced diabetic rat is a valid animal model for the study of hypoglycaemic and hypolipidemic activity of plant extract.

In spite of counter-regulatory factors avoiding the reduction in blood glucose levels by stimulating glucose production and limiting glucose utilization ${ }^{[26]}$, OB caused a significant reduce in blood glucose levels after a single oral administration in normal rats. OB may act rapidly in normal rats after a single oral administration but not chronically indicating that the observed hypoglycaemic effect of OB in normal rats is not cumulative during 15 days of oral administration. However, the hypoglycaemic effect was more apparent and cumulative over 15 days of oral administration in diabetic rats. Thus, aqueous $\mathrm{OB}$ extract possess a potent anti-hyperglycaemic effect in diabetic rats. In contrast, in untreated diabetic rats, blood glucose levels increased from the second day, due the insulinopenia and the consequent insulin resistance ${ }^{[27,28]}$. Plasma insulin levels were not affected by $\mathrm{OB}$ administration in normal and diabetic rats. Aqueous $\mathrm{OB}$ extract may act via inhibition of hepatic glucose production ${ }^{[29]}$ and/or renal glucose reabsorption ${ }^{30]}$, improving in vivo insulin action $^{[31]}$ or stimulation of glucose utilization by the peripheral tissues ${ }^{[32]}$.

Elevated plasma cholesterol and triglyceride levels are major risk factors of cardiovascular diseases ${ }^{[33]}$. Current hypoglycaemic agents allow a sharp control of blood glucose levels but insufficient correction of lipid 
Am. J. Pharm. \& Toxicol., 2 (3): 123-129, 2007

abnormality is observed especially hypertriglyceridemia ${ }^{[34]}$. Due to hyperglycaemia and insulin resistance, diabetic rats showed elevated plasma cholesterol and triglycerides levels ${ }^{[4]}$. Aqueous OB extract reduced total plasma cholesterol and triglycerides levels only in diabetic rats. Some studies have reported similar hypolipidemic activity in streptozotocin-induced diabetic rats ${ }^{[14-18]}$.

As no change in plasma insulin levels were observed after OB administration in normal and diabetic rats, the observed hypolipidemic effect seems independent of insulin action and may involve the inhibition of the key enzymes on cholesterol and triglycerides synthesis ${ }^{[35]}$ or increasing cholesterol excretion throughout bile acid formation ${ }^{[36]}$. However, it is not excluded that the observed hypolipidemic effect is mediated throughout the control of glycemia since the glycemic control is the major determinant of total cholesterol and triglyceride levels ${ }^{[37]}$, the evolution of glycemia was parallel to lipidic parameters in both normal and diabetic rats.

In conclusion, the aqueous extract of $\mathrm{OB}$ exhibits potent anti-hyperglycaemic and long term cholesterol and triglycerides lowering activity in STZ diabetic rats independently of insulin secretion. These results support its traditional use in the treatment of diabetes and cardiovascular disease. Finally, the precise mechanism (s) and site (s) of action of this activity and the active constituent (s) involved are still to be determined in addition to toxicological studies.

\section{REFERENCES}

1. Zimmet, P., 2000. Globalization, coca-colonization and the chronic disease epidemic: Can the Doomsday scenario be averted? J. Intern. Med., 247: 301-310.

2. Amos, A.F., D.J. McCarty and P. Zimmet, 1997. The rising global burden of diabetes and its complications: Estimates and projections to the year 2010. Diabet. Med., 14: S1-S85.

3. Wagman, A.S. and J.M. Nuss, 2001. Current therapies and emerging targets for the treatment of diabetes. Curr. Pharm. Des., 7: 417-450.

4. Goldberg, I.J., 2001. Clinical review 124: Diabetic dyslipidemia: Causes and consequences. J. Clin. Endocrinol. Metab., 86: 965-971.

5. Stern, M.P., B.D. Mitchell, S.M. Haffner and H.P. Hazuda, 1992. Does glycemic control of type II diabetes suffice to control diabetic dyslipidemia? A community perspective. Diabetes Care, 15: 638-644.
6. Marles, R.J. and N.R. Farnsworth, 1995. Antidiabetic plants and their active constituents. Phytomedicine, 2: 137-189.

7. Thompson Coon, J. S and Ernst, E. 2003. Herbs for serum cholesterol reduction: A systematic view. J. Fam. Pract., 52: 468-478.

8. Hooft, R., 2003. Drug discovery and development for metabolic diseases. Drug Discov. Today, 8: 1064-1066.

9. Eddouks, M., M. Maghrani, A. Lemhadri, M.L. Ouahidi and H. Jouad, 2002. Ethnopharmacological survey of medicinal plants used for the treatment of diabetes mellitus, hypertension and cardiac diseases in the south-east region of Morocco (Tafilalet). J. Ethnopharmacol., 82: 97-103.

10. Pederson, R.A., S. Ramanadham, A.M. Buchan, J.H. McNeill, 1989. Long-term effects of vanadyl treatment on streptozocin-induced diabetes in rats. Diabetes, 38: 1390-1395.

11. Gupta, D., J. Raju, J. Prakash, N.Z. Baquer, 1999. Change in the lipid profile, lipogenic and related enzymes in the livers of experimental diabetic rats: Effect of insulin and vanadate. Diabetes Res. Clin. Pract., 46: 1-7.

12. Harrigan, R.A., M.S. Nathan, P. Beattie, 2001. Oral agent for the treatment of type 2 diabetes mellitus: pharamcology toxicology and treatment. Ann. Emerg. Med., 38: 68-78.

13. Oubre, A.Y., T.J. Carlson, S.R. King, G.M. Reaven, 1997. From plant to patient: An ethnomedical approach to the identification of new drugs for the treatment of NIDDM. Diabetologia, 40: 614-617.

14. Bhandari, U., R. kanojia, K.K. Pillai, 2005. Effect of ethanolic extract of Zingiber officinale on dyslipidaemia in diabetic rats. J. Ethnopharmacol., 97: 227-230.

15. Eddouks, M., A. Lemhadri and J.B. Michel, 2005. Hypolipidemic activity of aqueous extract of Capparis spinosa L. in normal and diabetic rats. J. Ethnopharmacol., 98: 345-350.

16. Jouad, H., M. Eddouks, M.A. Lacaille-Dubois, B. Lyoussi, 2000. Hypoglycaemic effect of spergularia purpurea in normal and streptozotocininduced diabetic rats. J. Ethnopharmacol., 71: 169-177.

17. Jouad, H., A. Lemhadri, M. Maghrani, N.A. Zeggwagh, M. Eddouks, 2003. Cholesterollowering activity of the aqueous extract of Spergularia purpurea in normal and recent-onset diabetic rats. J. Ethnopharmacol., 87: 43-49. 
18. Kameswara Rao, B., M.M. Kesavulu, R. Giri, C. Appa Rao, 1999. Antidiabetic and hypolipidemic effects of Momordica cymbalaria Hook. fruit powder in alloxan-diabetic rats. J. Ethnopharmacol., 67: 103-109.

19. Wannissorn, B., S. Jarikasem, T. Siriwangchai and S. Thubthimthed, 2005. Antibacterial properties of essential oils from Thai medicinal plants. Fitoterapia, 76: 233-236.

20. Pavela, R., 2004. Insecticidal activity of certain medicinal plants. Fitoterapia, 75: 745-749.

21. Dasgupta, T., A.R. Rao and P.K. Yadava, 2004. Chemomodulatory efficacy of basil leaf (Ocimum basilicum) on drug metabolizing and antioxidant enzymes and on carcinogen-induced skin and forestomach papillomagenesis. Phytomedicine, 11: 139-151.

22. Vats, V., J.K. Grover, S. and S. Rathi, 2002. Evaluation of anti-hyperglycemic and hypoglycemic effect of Trigonella foenumgraecum Linn, Ocimum sanctum Linn and Pterocarpus marsupium Linn in normal and alloxanized diabetic rats. J. Ethnopharmacol., 79: 95-100.

23. Marti, L., A. Abella, C. Carpene, M. Palacin, X. Testar, A. Zorzano, 2001. Combined treatment with benzylamine and low dosages of vanadate enhances glucose tolerance and reduces hyperglycemia in streptozotocin-induced diabetic rats. Diabetes, 50: 2061-2068.

24. Junod, A., A.E. Lambert, W. Stauffacher, A.E. Renold, 1969. Diabetogenic action of streptozotocin: Relationship of dose to metabolic response. J. Clin. Investig., 48: 2129-2139.

25. Mathe, D., 1995. Dyslipidemia and diabetes: Animal models. Diabete. Metab., 21: 106-111.

26. Gerich, J.E., 1988. Glucose counterregulation and its impact on diabetes mellitus. Diabetes, 37: 1608-1617.
27. Blondel, O. and B. Portha, 1989. Early appearance of in vivo insulin resistance in adult streptozotocininjected rats. Diabete. Metab., 15: 382-387.

28. Yki-Jarvinen, H., 1990. Acute and chronic effects of hyperglycaemia on glucose metabolism. Diabetologia, 33: 579-585.

29. Eddouks, M., H. Jouad, M. Maghrani, A. Lemhadri and R. Burcelin, 2003. Inhibition of endogenous glucose production accounts for hypoglycemic effect of Spergularia purpurea in streptozotocin mice. Phytomedicine, 10: 594-599.

30. Eddouks, M. and M. Maghrani, 2004. Phlorizinlike effect of Fraxinus excelsior in normal and diabetic rats. J. Ethnopharmacol., 94: 149-154.

31. Hu, X.J., Y. Oshida, M. Xu, G. Bajotto and Y. Sato, 2003. Effect of Gosha-jinki-gan (Chinese herbal medicine: Niu-Che-Sen-Qi-Wan) on insulin resistance in streptozotocin-induced diabetic rats. Diabetes Res. Clin. Pract., 59: 103-111.

32. Welihinda, J and E.H. Karunanayake, 1986. Extrapancreatic effects of Momordica charantia in rats. J. Ethnopharmacol., 17: 247-255.

33. Nabel, E.G., 2003. Cardiovascular disease. N. Engl. J. Med., 349: 60-72.

34. Garg, A., 1994. Management of dyslipidemia in IDDM patients. Diabetes Care, 17: 224-234.

35. Zhang, Z., W.K. Ho, Y. Huang, A.E. James, L.W. Lam and Z.Y. Chen, 2002. Hawthorn fruit is hypolipidemic in rabbits fed a high cholesterol diet. J. Nutr., 132: 5-10.

36. Kim, S.H. and K.S. Park, 2003. Effects of Panax ginseng extract on lipid metabolism in humans. Pharmacol. Res., 48: 511-513.

37. Markku, L., 1995. Epidemiology of diabetes dyslipidemia. Diabetes Rev., 3: 408-422. 